\title{
Routes of spread of pathogens into the pancreas in a feline model of acute pancreatitis
}

\author{
A L Widdison, N D Karanjia, H A Reber
}

\begin{abstract}
The routes of spread of pathogens into the pancreas in acute pancreatitis were investigated. Four experiments were performed: (1) cats with and without acute pancreatitis were given $10^{7}$ Escherichia coli ( $E$ coli) intravenously, (2) in cats with acute pancreatitis $10^{8} E$ coli was placed in the colon. In half of them the colon was then enclosed in an impermeable bag to prevent transmural spread. (3) $E$ coli $\left(10^{4}\right)$ was placed in the pancreatic duct in cats with and without acute pancreatitis. (4) In cats with acute pancreatitis $10^{5} \mathrm{E}$ coli was placed in the gall bladder. In half of them the common bile duct was ligated to prevent biliary-pancreatic reflux. After 24 hours, intravenous $E$ coli infected the pancreas in six of nine cats with acute pancreatitis and three of 10 controls. After 72 hours $E$ coli spread to the pancreas from the colon in six of nine cats with acute pancreatitis. This was prevented by enclosing the colon in an impermeable bag $(p=0 \cdot 02)$. In five of six cats with acute pancreatitis and five of six controls $E$ coli placed in the pancreatic duct colonised the pancreas within 24 hours. Pancreatic colonisation from the gall bladder occurred in five of six cats with a patent common bile duct and in three of six with an obstructed common bile duct. In conclusion, in cats $E$ coli can spread to the pancreas by the blood stream, transmurally from the colon, and by reflux into the pancreatic duct.
\end{abstract}

(Gut 1994; 35: 1306-1310)

The pancreas is usually sterile and only becomes infected as a complication of associated disease processes such as acute pancreatitis. $^{1}$ A comparison of the typical pancreatic pathogens with the type of bacteria found in other sites in health or disease suggests several possible sources including the colon. ${ }^{12}$ In previous experiments we showed that pathogens may spread to the pancreas from the colon, gall bladder, and kidney. ${ }^{3}$ The only possible route of the spread of pathogens from the kidney is by the circulation whereas alternative routes were possible from the other sources. The aim of this study was to investigate routes by which pathogens could infect the pancreas.

\section{Methods}

Mr A L Widdison,

Department of Surgery,

Frenchay, Bristol BS16 1LE.

Accepted for publication

21 December 1993
MODEL OF ACUTE PANCREATITIS

The animal model of acute pancreatitis used has been described in detail previously ${ }^{4}$ and only a brief account will be given here. Fasted adult mongrel cats were used in all experiments. No antibiotics were given at any stage. Cats were anaesthetised with xylazine hydrochloride $(1 \mathrm{mg} / \mathrm{kg}$ body weight, intramuscular) and sodium pentobarbital (25 $\mathrm{mg} / \mathrm{kg}$ body weight, intraperitoneal). All operations were performed using an aseptic technique and infusions were made through in line bacterial filters $(0.2 \mu \mathrm{m}$ pore size).

A femoral vein was cannulated with a heparinised plastic catheter (external diameter $0.965 \mathrm{~mm}$ ). The abdomen was entered and the pancreatic duct was cannulated in the tail of the gland with a plastic catheter (external diameter $0.61 \mathrm{~mm}$ ) primed with standard perfusate. Acute pancreatitis was induced by perfusing $0.5 \mathrm{ml}$ of $7.5 \mathrm{mM}$ glycodeoxycholic acid into the pancreatic duct over one hour. Then $0.5 \mathrm{ml}$ of pooled pancreatic juice (activated by prior incubation with enterokinase) was perfused over a second hour. For two hours while the pancreatic duct was being perfused 16,16 dimethyl prostaglandin $\mathrm{E}_{2}(2 \mu \mathrm{g} / \mathrm{kg}$ body weight/hour) was infused intravenously to cause the development of acute pancreatitis. A similar procedure was performed in control animals except the pancreatic duct was perfused with standard perfusate for two hours and $0.9 \%$ isotonic saline was infused intravenously instead of prostaglandin $E_{2}$. Cats were then allowed to recover. Reoperation was performed on anaesthetised animals to remove tissues for microbiology.

\section{MICROBIOLOGICAL METHODS}

A clinical strain of $E$ coli was used as the marker pathogen. This strain had distinctive antimicrobial sensitivities so that it could be distinguished from endogenous $E$ coli. A precise number of $E$ coli was used in each experiment. These were counted immediately before administration using a Petroff-Hausser bacterial counting chamber. ${ }^{6}$

At the second operation specimens of pancreas, liver, lung, and kidney were removed. These were washed in sterile saline, blotted dry, homogenised, and then placed in brain heart infusion broth. In addition a venous blood sample was taken for culture to assess the bacteraemia rate, and bile was aspirated for culture in experiment 3 . Samples were incubated at $37^{\circ} \mathrm{C}$ for seven days. Standard microbiological techniques were used to isolate and identify $E$ coli and the concentration of $E$ coli in the pancreas and bile was estimated using a viable plate count method. ${ }^{6}$ 
The number of $E$ coli placed into each site and the timing of the reoperation to remove tissues for culture were estimated from preliminary experiments in which groups of cats received different numbers of $E$ coli by the different routes.

EXPERIMENTAL PROTOCOL

Four routes were studied.

Experiment 1: The vascular route

Preliminary experiments showed that $E$ coli spread to the pancreas within 24 hours after giving $10^{7} E$ coli or more as an intravenous bolus.

After the induction of acute pancreatitis $10^{7} \mathrm{E}$ coli were given as an intravenous bolus in nine cats. Ten control cats (no acute pancreatitis) were treated in the same way. Cats were allowed to recover and 24 hours later reoperation was performed and tissues were removed for culture.

\section{Experiment 2: The transmural route from the colon}

Preliminary experiments showed that $E$ coli did not spread to the pancreas within 24 hours despite giving $10^{10} \mathrm{E}$ coli. Translocation to the pancreas from the colon, however, did occur within 72 hours of placing $10^{8} \mathrm{E}$ coli into the colon.

In 17 cats acute pancreatitis was induced. At the end of this procedure $10^{8} E$ coli was injected through a 30 gauge needle inserted obliquely through the anti-pancreatic wall of the proximal transverse colon. To ensure that leakage from the needle puncture site did not occur a very fine needle was used and a microbiological swab of the puncture site was taken after injecting the $E$ coli. This was sterile in all the cats. In eight cats the transverse colon was then enclosed in a plastic bag, which was impermeable to the $E$ coli and was not bactericidal for $E$ coli. The colon was retained in the bag by three interrupted transmesenteric 3/0 dexon sutures (Figure). Care was taken to ensure the colon was not obstructed or the blood supply impaired. In the remaining nine cats $E$ coli was given and the colon replaced in the abdomen. It was not enclosed in a plastic bag. The laparotomy wound was closed and all cats were allowed to recover. Reoperation was performed 72 hours later and tissues were removed for culture.

Experiment 3: The pancreatic duct route Preliminary experiments showed that $E$ coli spread to the pancreas within 24 hours of placing $10^{4} \mathrm{E}$ coli or more into the pancreatic duct.

Acute pancreatitis was induced in six cats and then $10^{4} \mathrm{E}$ coli (in $0.1 \mathrm{ml}$ ) was placed in the pancreatic duct. Six control cats (no acute pancreatitis) were treated in the same way. The pancreatic catheter was then removed and the open end of the pancreatic duct ligated.
The laparotomy wound was closed and the cats allowed to recover. Reoperation was performed 24 hours later and tissues were removed for culture.

Experiment 4: The effect of common bile duct ligation on the spread of $\mathrm{E}$ coli from the gall bladder

Preliminary experiments showed that $E$ coli spread to the pancreas within 24 hours of placing $10^{5} \mathrm{E}$ coli or more into the gall bladder.

Acute pancreatitis was induced in 12 cats. At the end of the procedure cats were randomly divided into two equal groups. In six cats the supraduodenal common bile duct was ligated. In the remaining six cats the common bile duct remained patent. In all cats $10^{5} \mathrm{E}$ coli was then injected into the gall bladder through a 30 gauge needle. Reoperation was performed 24 hours later and tissues were removed for culture.

Experiments were approved by the office of research and development of the Sepulveda Veterans Administration Medical Center and conducted in accordance with the National Institute of Health Guide for Care and Use of Laboratory Animals. Cats were kept in individual cages and looked after in the animal house under the supervision of a veterinary surgeon and qualified technicians. Intramuscular buprenorphine $(0.005-0.01 \mathrm{mg} / \mathrm{kg}$ body weight, hourly as required, maximum eight doses) was provided for pain relief. At the end of each experiment anaesthetised animals were killed with an overdose of potassium chloride.

\section{STATISTICAL METHODS}

The pancreatic colonisation rates were compared using two tailed Fisher's exact test. The concentration of $E$ coli in the pancreas and bile was expressed as median (interquartile range) logarithm of the colony forming units ( $\log \mathrm{cfu}$ ) of $E$ coli per $\mathrm{ml}$ of bile or per gram of pancreas and results were compared using the Mann-Whitney U test.

\section{Results}

\section{EXPERIMENT 1}

An $E$ coli bacteraemia caused pancreatic colonisation in $67 \%$ (six of nine) of cats with acute pancreatitis and in $30 \%$ (three of 10 ) of control (no acute pancreatitis) cats $(p=0 \cdot 1)$. $E$ coli was also isolated from the liver, kidney, and lung in a similar proportion of animals. The concentration of $E$ coli in the inflamed gland, $1.6(3.1) \log \mathrm{cfu} / \mathrm{g}$ of pancreas, was not significantly different from the concentration in control glands, 1.7 (2) $\log \mathrm{cfu} / \mathrm{g}$.

\section{EXPERIMENT 2}

$E$ coli translocated from the colon to the pancreas in $67 \%$ (six of nine) of cats with acute pancreatitis in which the colon was not enclosed in a plastic bag. In cats with acute 


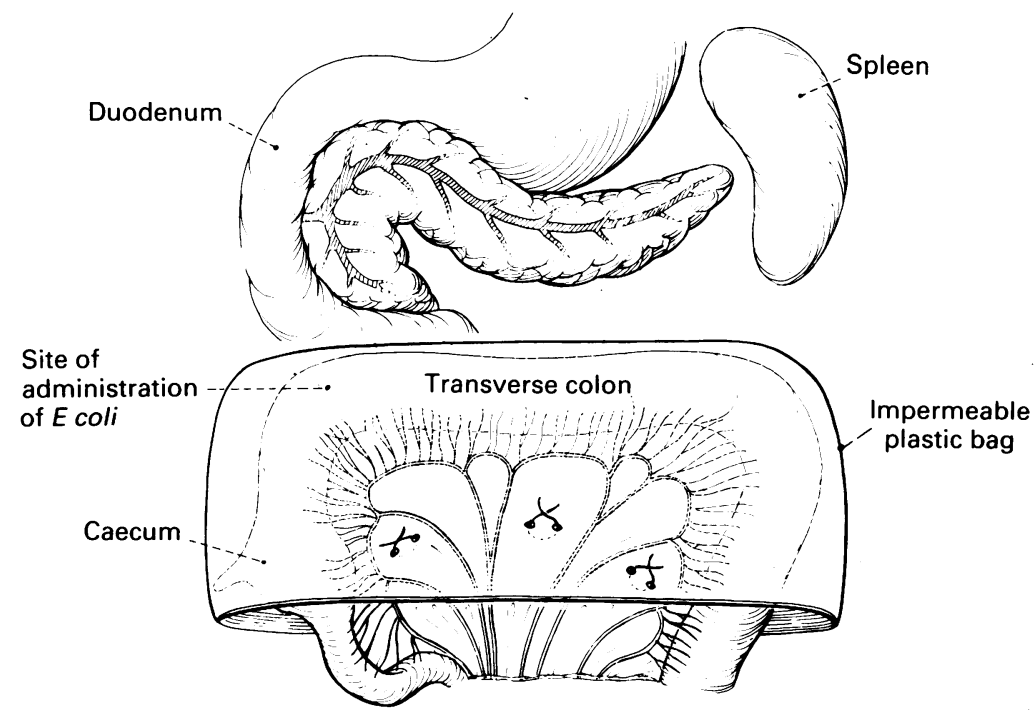

Line diagram to illustrate the method of enclosing the colon in an impermeable bag.

pancreatitis, however, in which the colon was enclosed in an impermeable bag, $E$ coli were not isolated from any of the pancreatic specimens $(\mathrm{p}=0.02) . E$ coli was isolated from the liver in two of the cats and from the lung in one cat in which the colon was enclosed by a plastic bag. The concentration of $E$ coli in glands colonised by $E$ coli was $2.93(1.86) \log$ $\mathrm{cfu} / \mathrm{g}$ of pancreas. $E$ coli was cultured from the circulation in five of nine cats (five of six cats with pancreatic colonisation) in the group where the colon was not enclosed in a bag but in none of the cats in which the colon had been enclosed in a plastic bag.

\section{EXPERIMENT 3}

$E$ coli placed in the pancreatic duct caused pancreatic colonisation equally (83\%; five of six) in cats with acute pancreatitis and control (no acute pancreatitis) animals. The concentration of $E$ coli in the inflamed gland, $2.79(0.37) \log \mathrm{cfu} / \mathrm{g}$ of pancreas, was not different from the concentration in control glands, $2.51(1.89) \log \mathrm{cfu} / \mathrm{g}$. $E$ coli was cultured from the blood taken at reoperation (bacteraemia rate) in only one cat with acute pancreatitis and pancreatic colonisation from the pancreatic duct (one of 10 cats with pancreatic colonisation).

\section{EXPERIMENT 4}

In cats with acute pancreatitis $E$ coli translocated from the gall bladder to the pancreas and other organs despite ligating the common bile duct. Pancreatic colonisation occurred in five of six cats with a patent common bile duct and in three of six cats with an obstructed duct $(p=0 \cdot 3)$. The concentration of $E$ coli in the bile was about $10^{7} \mathrm{cfu} / \mathrm{ml}$ of bile in all cats. The concentration of $E$ coli isolated from pancreatic specimens in each group was similar: 3.39 (3.12) $\log \mathrm{cfu} / \mathrm{g}$ of pancreas in cats with a patent common bile duct, 4.34 (1.95) log $\mathrm{cfu} / \mathrm{g}$, in cats with an obstructed common bile duct. $E$ coli was isolated from blood taken at reoperation in three of six cats in each group. Among cats with a patent common bile duct with pancreatic colonisation the bacteraemia rate was three of five $(\mathrm{p}=0.004 v$ the bacteraemia rate, one of 10 , when the pancreas was colonised from the pancreatic duct), and three of three cats with pancreatic colonisation despite ligating the common bile duct $(p=0.01$ $v$ the bacteraemia rate, one of 10 , when the pancreas was colonised from the pancreatic duct).

\section{Discussion}

Pancreatic infection is the principal life threatening complication of acute pancreatitis. Patients with necrotising acute pancreatitis are at increased risk of developing pancreatic infection. ${ }^{1} 2788$ For this reason an animal model of acute necrotising pancreatitis was used.

This was a qualitative study and for this reason the number of $E$ coli given to each of the sites was the minimum number associated with translocation to the pancreas as determined by preliminary experiments. Physiological numbers of $E$ coli were used in each of the experiments. The median concentration of $E$ coli in the circulation after a bolus intravenous injection of $10^{7} \mathrm{E}$ coli was 68 $\mathrm{cfu} / \mathrm{ml}$. This concentration is found in more than $10 \%$ of bacteraemias clinically. ${ }^{9-11}$ The typical concentration of $E$ coli in faeces is $10^{8} \mathrm{cfu} / \mathrm{g}$. A bolus of $10^{8} \mathrm{E}$ coli will probably not change the host flora. The concentration of $E$ coli isolated from bile in this study $\left(10^{7} \mathrm{cfu} / \mathrm{ml}\right)$ was similar to that found in patients with bactobilia. ${ }^{12}$ If only $0.1 \mathrm{ml}$ of infected bile refluxed into the pancreatic duct the pancreas would be exposed to $10^{6} \mathrm{E}$ coli. $10^{4} E$ coli was placed in the pancreatic duct in this study.

Previously we have shown that $E$ coli may spread to the pancreas from the colon, gall bladder, and kidney. ${ }^{3}$ The only route of spread of pathogens common to each of these sites is by the circulation. Here we showed that a transient bacteraemia caused pancreatic colonisation in both control cats and cats with acute pancreatitis. This is an important finding because bacteraemias may arise spontaneously from the biliary and gastrointestinal tract, from urinary tract or respiratory tract infections, by direct shedding from venous cannulas or during invasive procedures. ${ }^{9-11}$ Most bacteraemias are rapidly cleared by the reticuloendothelial system. ${ }^{5}{ }^{13-15}$ A proportion, however, of circulating bacteria is deposited in organs throughout the body. ${ }^{16} 17$ Indeed, in this study $E$ coli was isolated from the liver, lung, and kidney in addition to the pancreas. Bacteraemias are a recognised cause of pyelonephritis, brain abscesses, endocarditis, septic arthritis, and osteomyelitis 9161819 and must now be implicated in the pathogenesis of pancreatic infection. Furthermore, in acute pancreatitis the risk of organ colonisation and subsequent infection is increased because the rate of clearance of $E$ coli from the circulation is reduced. ${ }^{5}$ 
The transverse colon is generally considered the most probable source of pancreatic pathogens because of its proximity to the pancreas and because pancreatic pathogens are normal members of the colonic microbial flora. ${ }^{20-22}$ Previous studies from this laboratory and others have shown that pathogens can spread from the colon to the pancreas. ${ }^{3} 23$ Pathogens may spread to the pancreas either directly across the bowel wall (transmural route) or by the circulation. It would be very difficult to prove either or these routes. If the transmural route was blocked, however, then any spread that occurred must be by the circulation. In this study we found that enclosing the colon in an impermeable plastic bag to block the transmural route prevented the spread of $E$ coli to the pancreas. The bag was not bactericidal and postoperatively there was no evidence of functional or mechanical interference with bowel function. Indeed, if there had been the likelihood of spread from the colon to the pancreas would have been increased not decreased. This suggested that the most important route of spread of $E$ coli from the colon was the transmural route at this time interval. Other routes, however, such as by the lymphatic system and the circulation at later time intervals, were not ruled out by this study. In support of the transmural route other animal experiments have shown that bacteria translocate from the colon into the pancreas ${ }^{323}$ and nearby intra-abdominal abscesses 2425 or into an inflamed peritoneal cavity 2426 without seeming to spread by the blood stream.

The mechanisms by which the transmural spread of bacteria occurs are incompletely understood. ${ }^{24}$ One theory is that colonic macrophages migrate into nearby areas of inflammation. Some of these macrophages may carry viable pathogens, which are then released and in the presence of dead and devitalised tissue can multiply.

Bile is a potential source of pancreatic pathogens that has received scant attention. The spectrum of biliary and pancreatic pathogens are similar and previously we have shown that $E$ coli can spread from the bile to the pancreas. ${ }^{3}$ Of the many possible routes by which biliary bacteria could spread to the pancreas the most likely is biliarypancreatic reflux. Pancreatic and bile duct pressures vary widely so that although the mean pressure in the pancreatic duct is higher than in the common bile duct ${ }^{27-29}$ there are occasions when the pressure difference is reversed and reflux occurs. ${ }^{30}$ Here we have shown that pathogens placed in the pancreatic duct may cause pancreatic infection. This finding supports previous studies performed using different animal models of acute pancreatitis $^{31}$ and either a higher concentration of $E$ coli or $E$ coli in combination with Bacteroides fragilis. ${ }^{32}$

Ligation of the common bile duct to prevent biliary-pancreatic reflux did not prevent the spread of $E$ coli from the gall bladder. This suggested other routes of spread were possible. Biliary tract obstruction, however, may have artifactually promoted the spread of $E$ coli by causing biliary hypertension and ascending cholangitis. Cholangiovenous reflux may occur in an obstructed biliary tract. ${ }^{33} 34$ In patients with biliary acute pancreatitis the common bile duct is obstructed, at least transiently, during the passage of a calculus. ${ }^{35} 36$ In these patients bacteria may spread from the biliary tract to the pancreas by the circulation. In support of the cholangiovenous route, the bacteraemia rate among cats with pancreatic colonisation caused by $E$ coli from the gall bladder whether or not the common bile duct was ligated was greater than the rate among cats with pancreatic colonisation directly from the pancreatic duct. As the pancreas was colonised in both groups of animals it is probable that the increased bacteraemia rate resulted from the shedding of $E$ coli into the circulation from the biliary tract.

In conclusion, in cats pathogens may reach the pancreas by several routes. $E$ coli can spread to the pancreas by the blood stream, transmurally from the colon, and by reflux into the pancreatic duct. This suggests it would be difficult to prevent bacteria from reaching the pancreas.

1 Widdison AL, Alvarez C, Reber HA. Surgical intervention in acute pancreatitis: when and how. Pancreas 1991; 6: S44-51.

2 Widdison AL, Karanjia ND. Pancreatic infection complicating acute pancreatitis. Br $\mathcal{F}$ Surg 1993; 80: 148-54.

3 Widdison AL, Karanjia ND, Alvarez C, Reber HA. Sources of pancreatic pathogens in acute pancreatitis. Gastroenterology 1991; 100: A304.

4 Widdison AL, Alvarez C, Reber HA. The low pressure duct perfusion model of acute pancreatitis. Eur Surg Res 1992; 24: S55-61.

5 Widdison AL, Karanjia NA, Alvarez C, Reber HA. Reticulo-endothelial system function and the influence of levamisole on the development of pancreatic infection in acute necrotizing pancreatitis. Am $\mathcal{f}$ Surg 1992; 163: $100-4$.

6 Carlberg DM. Determining the effect of antibiotics on bacterial growth by optical and electrical methods. In: Lorimar V, ed. Antibiotics in laboratory medicine. Baltimore: Williams and Wilkins, 1986: 64-92.

7 Roscher R, Berger HG. Bacterial infection of pancreatic necrosis. In: Beger HG, Buchler M, eds. Acute pancreatitis. necrosis. In: Beger HG, Buchler M, eds.

8 Buchler M, Malfertheiner P, Friess H, Isenmann R, Vanek $\mathrm{E}$, Grimm H, et al. Human pancreatic tissue concentraE, Grimm H, et al. Human pancreatic tissue concentration of bact

9 Scheld WM, Sande MA. Cardiovascular infections. In: Mandell GL, Douglas RG, Bennett JE, eds. Principles and practice of infectious diseases. New York: John Wiley, 1984: $504-15$.

10 Kreger BE, Craven DE, Carling PC, McCabe WR. Gram negative bacteremia. III. Reassessment of etiology, epidemiology and ecology in 612 patients. Am Med $\mathcal{F}$ 1980; 68: 332-44.

11 Everett ED, Hirschmann JV. Transient bacteremia and endocarditis prophylaxis. A review. Medicine 1977; 56: 61-77.

12 Keighley MRB. Infection and the biliary tree. In: Blumgart LH, ed. The biliary tract. London: Chuchill Livingstone, 1982: 219-35.

13 Rogers DE. Host mechanisms that act to remove bacteria from the blood stream. Bacteriol Rev 1960; 24: 50-66.

14 Benacerraf B, Sebestyen MM, Schlossman S. A qualitative study of the kinetics of blood clearance of P-32 labelled E coli and Staphylococci by the RES. F Exp Med 1959, 110: $27-48$.

15 Scott-Conner CH, Grogan JB, Scher KS, Bernstein J. Impaired clearance of $\mathrm{E}$ coli bacteremia in early biliary obstruction. Am F Surg 1989; 157: 210-4.

16 Brenner BM. Urinary tract infection, pyelonephritis and reflux nephropathy. In: The kidney. Philadelphia: WB Saunders, 1981: 1571-632.

17 Steffen EK, Berg EK, Deitch EA. Comparison of translocation rates of various indigenous bacteria from the gastrointestinal tract to the mesenteric lymph node gastrointestinal tract to the

18 Zak O, Sande MA. Experimental models in antimicrobial chemotherapy. London: Academic Press, 1986.

19 Mandell GL, Douglas RG, Bennett JE. Principles and practice of infectious diseases. New York: John Wiley, 1984. 
20 Warshaw AL. Pancreatic abscesses. N Engl f Med 1972; 287: 1234-6.

21 Farringer JL, Robbins LB, Pickens DR. Abscesses of the pancreas. Surgery 1966; 60: 964-70.

22 Beger HG, Bittner R, Block S, Buchler M. Bacterial contamination of pancreatic necrosis: a prospective clinical study. Gastroenterology 1986; 91: 433-8.

23 Hancke E, Marklein G. Bacterial contamination of the pancreas with intestinal germs: a cause of acute suppurative pancreatitis? In: Berger HG, Buchler M, eds. Acute pancreatitis. Berlin: Springer-Verlag, 1987: 87-9.

24 Wells CL, Maddaus MA, Simmons RL. Proposed mechanisms for the translocation of intestinal bacteria. Rev Infect Dis 1988; 10: 958-79.

25 Wells CL, Rotstein OD, Pruett TL, Simmons RI. Intestinal bacteria translocate into experimental intraabdominal abscesses. Arch Surg 1986; 121: 102-7.

26 Schweinburg FB, Seligman AM, Fine J. Transmural migration of intestinal bacteria. $N$ Engl f Med 1950; 242: migratio

27 Armstrong CP, Taylor TV. Pancreatic duct reflux and acute gallstone pancreatitis. Ann Surg 1986; 204: 59-64

28 Gregg JA, Carr-Locke DL. Endoscopic pancreatic and biliary manometry in pancreatic, biliary and papillary disease and after endoscopic sphincteroplasty and surgical sphincteroplasty. Gut 1984; 25: 1247-54.
29 Carr-Locke DL, Gregg JA. Endoscopic manometry of pancreatic and biliary sphincter zones in man. Dig Dis $\mathrm{Sci}$ 1981; 26: 7-15.

30 Taylor TV, Rimmer S. Pancreatic duct reflux in patients with gallstone pancreatitis. Lancet 1980; i: 848-50.

31 Semsch B, Heitz G, Berger G, Haring R. Influence of $\mathrm{E}$ coli on the course of acute pancreatitis in mini pigs. In: Beger HG, Buchler M, eds. Acute pancreatitis. Berlin: Springer-Verlag, 1987: 90-9.

32 Tarpila E, Nystrom PO, Franzen L, Lilja I, Ihse I. Acute experimental suppurative pancreatitis in the rat. Acta Chir experimental suppurative pan

33 Lygidakis NJ, Brummelkamp WH. Bacteremia in relation to intrabiliary pressure in proximal $\mathrm{v}$ distal malignant biliary obstruction. Acta Chir Scand 1986; 152: 305-7.

34 Huang $T$, Bass JA, Williams RD. The significance of biliary pressure in cholangitis. Arch Surg 1969; 98: 629-32.

35 Neoptolemos JP, Carr-Locke DL, Leese T, James D. Acute cholangitis in association with acute pancreatitis: incicholangitis in association with acute pancreatitis: inciand endoscopic sphincterotomy. Br $f$ Surg 1987; 74: 1103-6.

36 Williamson RCN. Early assessment of severity in acute pancreatitis. Gut 1984; 25: 1331-9. 